\title{
Antigravity hills are visual illusions
}

\author{
Paola Bressan, ${ }^{1}$ Luigi Garlaschelli, ${ }^{2}$ and Monica Barracano ${ }^{1}$ \\ ${ }^{1}$ Università di Padova, Padova, Italy and ${ }^{2}$ Università di Pavia, Pavia, Italy
}

\begin{abstract}
Antigravity hills, also known as spook hills or magnetic hills, are natural places where cars put into neutral are seen to move uphill on a slightly sloping road, apparently defying the law of gravity. We show that these effects, popularly attributed to gravitational anomalies, are in fact visual illusions. We recreated all the known types of anti-gravity spots in our laboratory using tabletop models; the number of visible stretches of road, their slant, and the height of the visible horizon were systematically varied in four experiments. We conclude that these effects follow from a misperception of the eye level relative to gravity, caused by the presence of contextual inclines or a false horizon line.
\end{abstract}

Address correspondence to Paola Bressan, Dipartimento di Psicologia Generale, Università di Padova, Via Venezia 8, 35131 Padova, Italy; e-mail: paola.bressan@unipd.it.

Antigravity hills (also known as gravity hills, spook hills, or magnetic hills) are natural places where cars put into neutral are seen to move uphill on a slightly sloping road, apparently defying the law of gravity. Typically, the "spooky" stretch of road is rather short (50-90 m), only a few meters wide, and surrounded by a natural hill landscape, without nearby buildings.

Such places are found in several countries all around the world, ${ }^{1}$ and have been tourist attractions for decades. They should not be confused with the "mystery spots" found in amusement parks. These are generally tilted cabins, purposely built as such; a person walking inside feels disoriented, getting a very strong impression of standing at an angle in a perfectly normal room (Gregory, 1998; Shimamura \& Prinzmetal, 1999).

The effects experienced on spook hills are so impressive that people account for them by appealing to physical (magnetic or gravitational) anomalies; these are indeed the only explanations offered to the tourists on site. Magnetic causes can be ruled out easily, because the effects are visible even on nonmagnetic materials, such as plastic balls or water poured on the ground. The other favorite explanation is that in these locations the force of gravity is

\footnotetext{
${ }^{1}$ We are aware of antigravity hills at the following locations. United States: Confusion Hill , Idelwild Park, Ligonier, Pennsylvania; Gravity Hill , northwest Baltimore County, Maryland; Gravity Hill , State Route 42, Mooresville, Indiana; Gravity Hill , State Route 96, south of New Paris, Bedford County, Pennsylvania; Gravity Hill, White's Hill, Rennick Road, La Fayette County, Wisconsin; Gravity Road, Ewing Road, Route 208, Franklin Lakes, Washington; Mystery Hill , Highway 321, Blowing Rock, North Carolina; Mystery Spot, Putney Road, Benzie County, Michigan; Spook Hill , North Wales Drive, North Avenue, Lake Wales, Florida; Spook Hill , Gapland Road, Burkittsville, Frederick County, Maryland.

Canada: Gravity Hill, McKee Road, Ledgeview Golf Course, Abbotsford, British Columbia; Magnetic Hill , Neepawa, Manitoba; Magnetic Mountain , Canada Highway, Moncton, New Brunswick.

Europe: Ariccia , Rome, Italy; Electric Brae , A719, Croy Bay, Ayr, Ayeshire, Scotland; Malveira da Serra , Road N247, Lisbon, Portugal; Martina Franca , Taranto, Italy; Montagnaga , Trento, Italy; Mount Penteli , Mount Penteli, Athens, Greece.

Other countries: Anti-Gravity Hill , Straws Lane Road, Wood-End, Victoria, Australia; Morgan Lewis Hill , St. Andrew, Barbados; Mount Halla , Cheju Do Island, South Korea.
} 
not directed toward the earth's center, but slightly tilted, for some unknown reason.

However, the inclination of several such roads has been measured using spirit levels, and the actual slope has always been found to be opposite to the apparent one. To prevent the objection that gravitational anomalies would influence the level as well, in at least one case (Montagnaga, Italy) researchers also took measurements from a distance (i.e., away from the spooky stretch of road) by using a professional surveyor's instrument, a theodolite (Polidoro \& Garlaschelli, 2001). The parallelism between a plumb line hanging within the critical area and another outside it was first checked; then, height quotes were taken on graduated yardsticks. The real slope was calculated to be about $1 \%$ and opposite in direction to the apparent slope.

The most economical explanation for antigravity hills is that they are visual illusions in the natural environment. In this article, we report four experiments showing that these phenomena can be reproduced in the laboratory, and suggest that they are due to the visual anchoring of the spooky surface to a gravity-relative eye level whose perceived direction is biased by the sloping surrounds.

\section{EXPERIMENT 1}

In Experiment 1, we used a tabletop model with three hinged moveable boards to investigate the case in which the critical spot is a sloping stretch of road between two other stretches that both run either uphill or downhill (as one moves forward from the observation point at one end). Because our model was $2.40 \mathrm{~m}$ long, devoid of visible texture, and viewed monocularly through a reduction screen, most depth cues (aerial perspective, texture gradients, and binocular cues such as disparity and convergence) were absent.

\section{Method}

The tabletop model is schematically shown in Figure 1, and described in detail in the appendix. We used five different inclinations for the boards, relative to the observer's viewpoint: horizontal, 1.5\% uphill (a rise of $3 \mathrm{~cm}$ over $2 \mathrm{~m}$ ), 3\% uphill (a rise of $6 \mathrm{~cm}$ over 2 $\mathrm{m}$ ), 1.5\% downhill (a negative rise of $3 \mathrm{~cm}$ over $2 \mathrm{~m}$ ), and $3 \%$ downhill (a negative rise of $6 \mathrm{~cm}$ over $2 \mathrm{~m}$ ). In every trial, board $B$ (the middle one) was given one of these five rises, and boards $A$ (the closest to the observer) and $C$ (the farthest away) were both given the same rise. Thus, there were $25(5 \times 5)$ possible conditions, or combinations of slants.

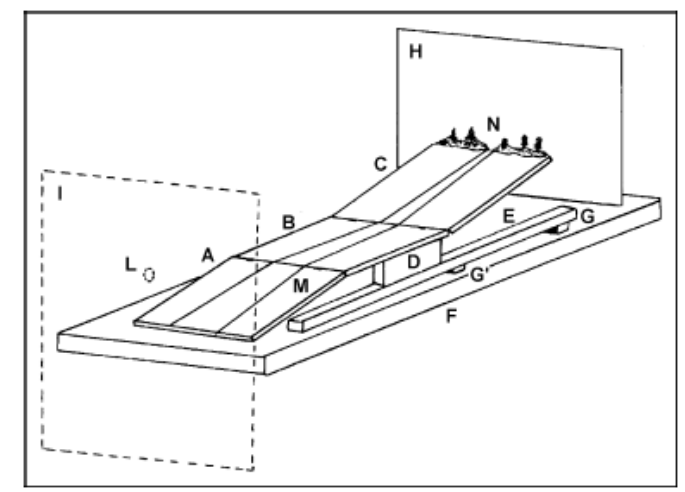

Fig. 1. Schematic illustration of the tabletop model used in Experiment 1. See the appendix for details.

Sixty undergraduate students ( 30 females and 30 males) participated as subjects. They were divided into three groups of 20 subjects each; each group saw 2 or 3 of 8 conditions. For completeness, the remaining 17 conditions were shown to a different sample of 6 observers. 
All subjects were unaware of the actual setup and of the purpose of the experiment. Observers sat, one at a time, in front of screen I. They were asked to look into hole $L$, describe what they saw, and then assess the slope of the three stretches $A, B$, and $C$ on a 5point scale, where $-2=$ strongly downhill, $-1=$ slightly downhill, $0=$ horizontal, $1=$ slightly uphill, and 2 = strongly uphill. Each trial was followed by a break of about $1 \mathrm{~min}$, during which the hole was occluded and the model modified.

\section{Results}

\section{Slants are underestimated}

Three stretches with the same slant were seen as horizontal by all subjects, whether they were truly horizontal, $1.5 \%$ downhill, or $1.5 \%$ uphill. However, three $3 \%$-downhill or $3 \%$-uphill stretches were always perceived, respectively, as (slightly) downhill and (slightly) uphill.

\section{Perceived slant depends on contextual inclines}

Figure 2 shows how the apparent slope of the middle stretch was affected by the inclines that preceded and followed it. A slightly downhill stretch between two strongly downhill inclines was seen as illusorily uphill by 16 subjects out of 20 , and as illusorily horizontal by the other 4 (top panel, left-most filled symbol); this condition reproduced the natural case of Gravity Hill in Pennsylvania. However, a slightly uphill stretch between two strongly uphill inclines (i.e., the physically symmetrical condition) was seen by all subjects as level, not as downhill (bottom panel, right-most open symbol). This result implies that inducing an illusory downhill is not nearly as easy as inducing an illusory uphill. (Experiment 2 showed that it requires steeper inducing slopes.) A horizontal stretch between two downhill inclines was always seen as illusorily uphill (top panel, two left-most open symbols), whereas uphill inclines failed to make it appear downhill (two right-most open symbols). Also, a 3\%-downhill middle stretch, although it never reversed in slope, could be made to look horizontal when accompanied by any nondownhill stretch $(13,7$, and 7 of 20 responses were "horizontal" for the horizontal, slightly uphill, and strongly uphill contextual stretches, respectively), but a $3 \%$-uphill middle stretch appeared uphill to all subjects in all conditions.

This asymmetry between uphill and downhill stretches was also apparent in the way the apparent slopes of the first and third stretches (which always had the same inclination) were modulated by the middle incline. Two horizontal stretches appeared uphill when separated by a downhill slope (72 of 80 responses were "uphill"; 20 subjects across two stretches and two conditions), but failed to look downhill when separated by an uphill slope (24 of 24 responses were "horizontal"; 6 subjects across two stretches and two conditions). A slightly downhill farther stretch preceded by a steeper downhill could look uphill (out of 20 responses, 8 were "uphill" and 11 were "downhill"), but a slightly uphill farther stretch preceded by a steeper uphill appeared level to all subjects, and never downhill.

In summary, then, Experiment 1 showed that small slant angles are underestimated relative to the horizontal plane, and that horizontal stretches, or slight downhills, can appear uphill when accompanied by steeper downhills. 


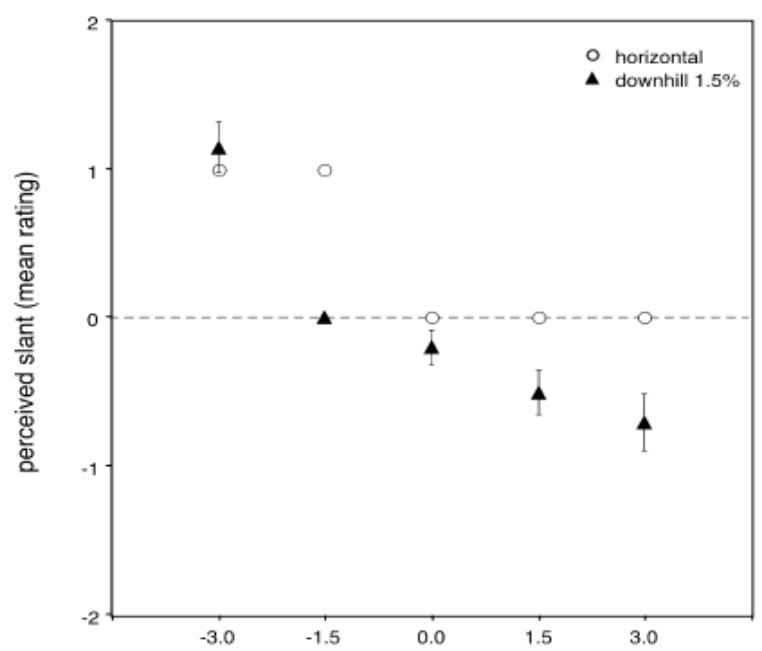

physical slant of contextual stretches (\%)

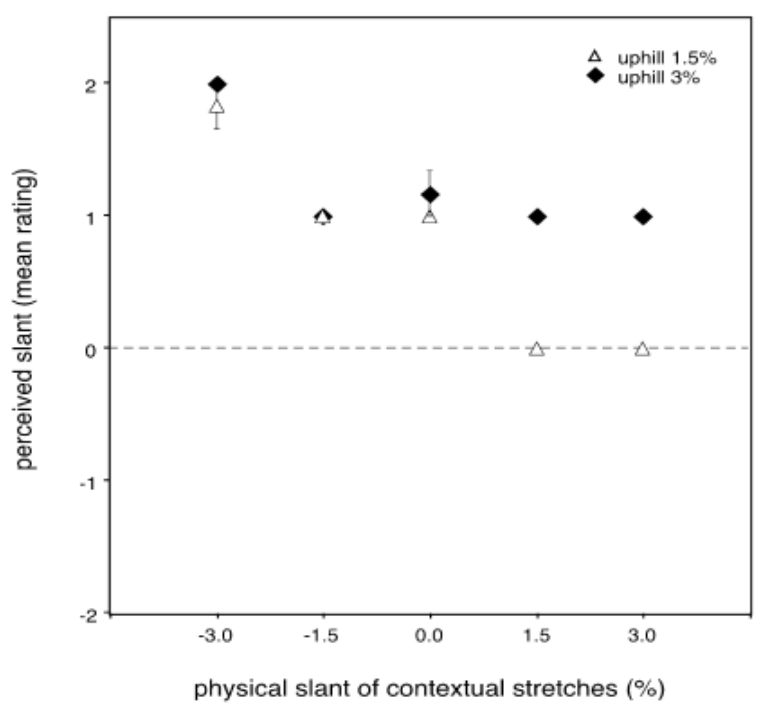

Fig. 2. Results from Experiment 1. Perceived slant (mean rating on the 5-point scale) of the middle stretch (board B; see Fig. 1) is graphed as a function of the physical slant of the nearer and farther stretches (boards A and C, respectively), for four different physical slants of B: horizontal and $1.5 \%$ downhill (top panel) and 1.5\% uphill and 3\% uphill (bottom panel). Bars indicate the standard error of the mean.

\section{EXPERIMENT 2}

In Experiment 2, we studied the special case in which there are two, rather than three, visible stretches of road. Most popular spots, such as Spook Hill (Florida), Magnetic Hill (Canada, shown in Fig. 3), and Ariccia (Italy), belong to this class. In these places, stopped cars that are put into neutral on the apparent downhill stretch of road that precedes the uphill one roll backwards as though repelled by a mysterious force (described, at Spook Hill, as "the curse of the Indian Chief"). 


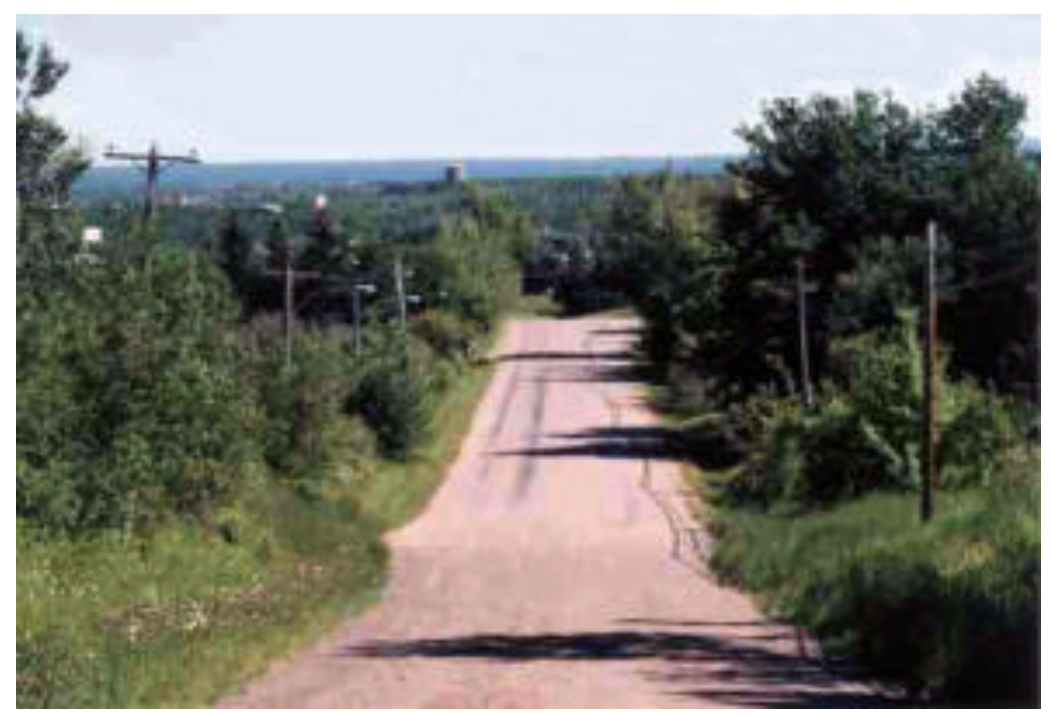

Fig. 3. Magnetic Hill (Canada). The nearer stretch of road is misperceived as running downhill.

\section{Method}

The tabletop model was similar to the one used in Experiment 1, but two rather than three boards were used. The boards measured $100 \times 120 \mathrm{~cm}$ each, and were hinged to each other so as to give a plane of $100 \times 240 \mathrm{~cm}$. They could be lifted or lowered independently by two lab jacks.

Eight different conditions were presented in random order. In four conditions, the first stretch ran slightly uphill (1.5\%), and the second stretch was horizontal or uphill $(3 \%, 6 \%$, or $9 \%)$. In the other four, the first stretch was downhill (3\% or $6 \%$ ), and the second stretch was either horizontal or slightly downhill (1.5\%).

Eight undergraduate and graduate students who had not participated in the previous experiment served as subjects.

\section{Results}

The apparent slope of a slightly uphill first stretch was a function of the physical slope of the second, $\chi^{2}(3, N=8)=16.9, p=.0007$ (Friedman two-way analysis of variance), as can be seen in Figure 4. Although it was always actually uphill, the first stretch was seen as such only when the second stretch was horizontal. As the slope of the second stretch increased, the first stretch was viewed first as level (thus replicating the lack of slope reversal in the comparable condition of Experiment 1, in which a 1.5\%-uphill stretch between two 3\%-uphill inclines was always seen as horizontal) and then as increasingly downhill. The most extreme condition (right-most filled symbol in Fig. 4) reproduced very well the illusions seen at Spook Hill and Magnetic Hill, and the illusion seen at Ariccia when one watches the critical spot from the viewpoint opposite the standard one (see Fig. 5, top panel). The stretch of road in the background is veridically seen as strongly uphill, and the stretch of road in the foreground is erroneously seen as downhill. 


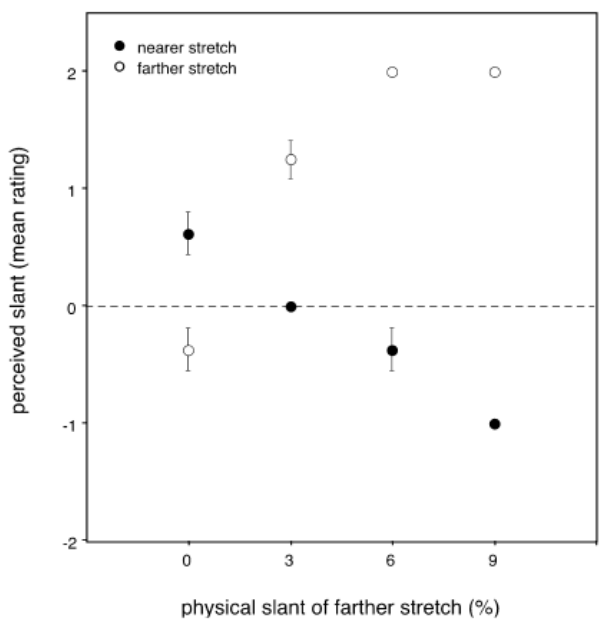

Fig. 4. Results from Experiment 2. Perceived slant (mean rating on the 5-point scale) of nearer and farther stretches is graphed as a function of the physical slant of the farther stretch. The nearer stretch was always $1.5 \%$ uphill. Bars indicate the standard error of the mean.
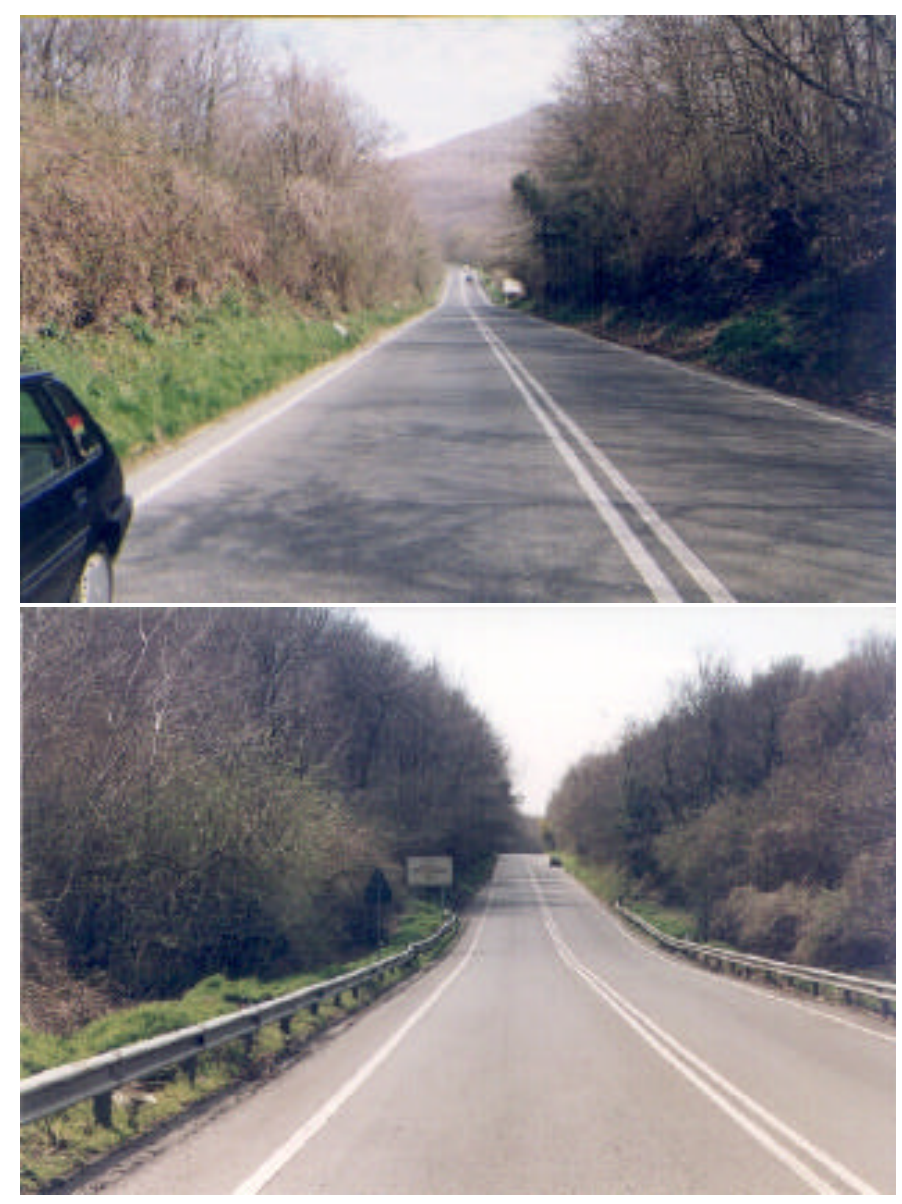

Fig. 5. Ariccia (Italy). The "standard" view is shown in the bottom photograph. From this viewpoint, the farther stretch of road is misperceived as running uphill. The top photograph shows the view from the opposite end of the road. From this viewpoint, the nearer stretch of road is misperceived as running downhill.

A horizontal stretch preceded by a downhill was perceived as uphill by all subjects; a $1.5 \%$ downhill preceded by a $3 \%$ downhill was also reported as uphill by all subjects. The latter 
condition reproduced exactly the illusion seen at Ariccia when the spooky spot (whose physical slope is about $1 \%$ ) is watched from the standard viewpoint. The stretch of road in the foreground is seen as sloping downhill very gently (but it is in fact steeply downhill), and the stretch of road in the background is erroneously seen as uphill (but it is actually downhill; see Fig. 5 , bottom panel).

Thus, Experiment 2 showed not only that illusory slope reversal also occurs in a two-stretch condition, but also that slight uphills can turn into perceptual downhills, too-provided they are followed by much steeper uphills.

\section{EXPERIMENT 3}

In Experiment 3, we studied the case in which two roads with different slopes depart from a crossing on a hillside. One such case (Montagnaga, Italy) is shown in Figure 6.

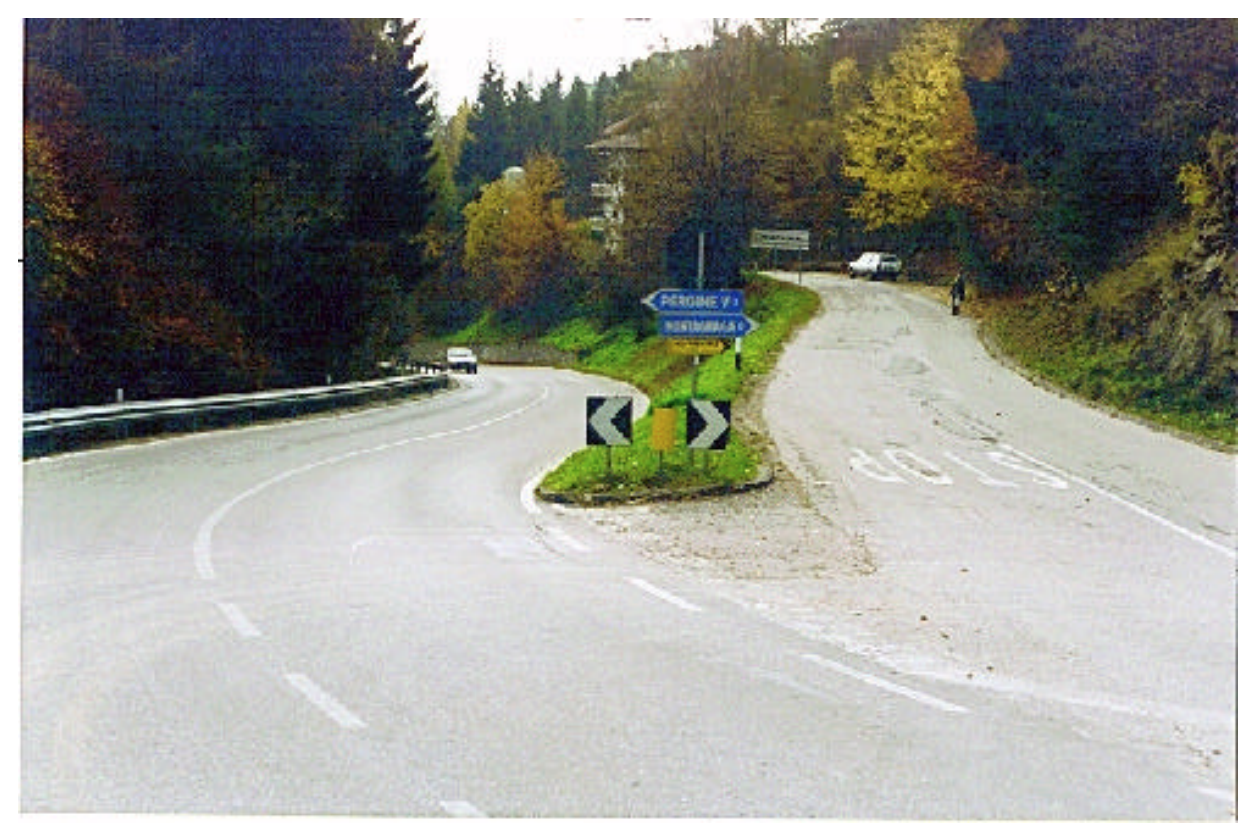

Fig. 6. Montagnaga (Italy). The road on the right is misperceived as running uphill.

\section{Method}

A sloping landscape similar to a hillside was created on a large level table, by fitting a thin green cloth on a number of aligned supporting blocks of decreasing sizes (Fig. 7). Relative to the observer, the terrain was high on the left, and sloped down toward the right border of the model at an angle of about $15^{\circ}$.

The roads were constructed with two triangular boards, each $7 \times 200 \mathrm{~cm}$, covered with tancolored textureless paper. These roads departed from nearby positions at the same height, as they were both resting on a single block placed just below the observation hole, and were seen as converging on the sloping horizon line of the "hillside." The far ends of the two boards could be lifted or lowered independently.

A rectangular piece $(100 \times 40 \mathrm{~cm})$ of brown cardboard could be interposed between the "hill" and the "sky" to simulate a faraway horizon. The cardboard could be lifted to different positions, so that subjects could see the horizon at five different heights: lower than both roads (i.e., not visible to the viewer), higher than both roads, in an intermediate position, at 
the vanishing point of the right (lower) road, or at the vanishing point of the left (higher) road. The reduction screen and the sky background were the same as in Experiment 1. The procedure was also identical.

Eleven different conditions were obtained by changing the slopes of the two roads; each condition was shown with each of the five horizon heights, for a total of 55 trials, presented in random order. Eight members of the University of Padova (Italy) community, none of whom had participated in the previous experiments, served as observers.

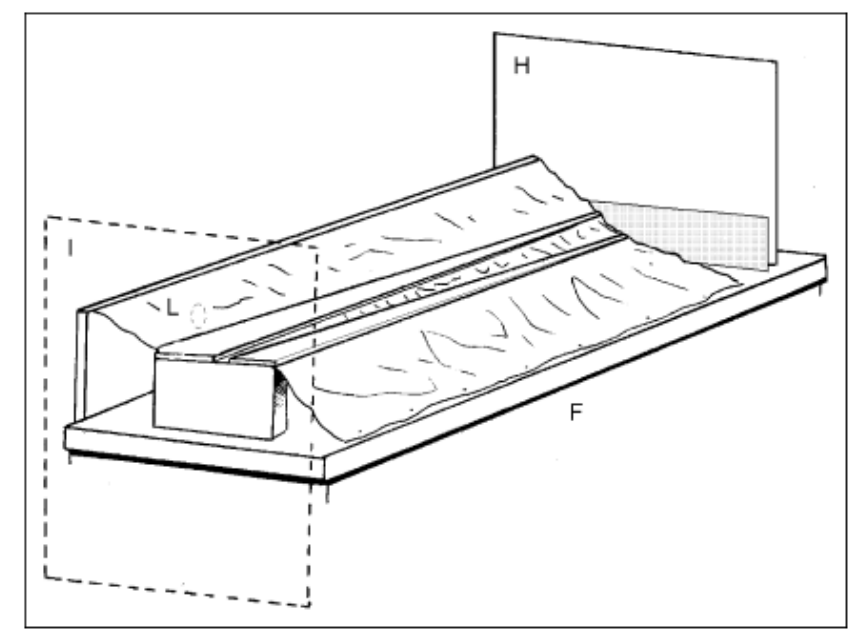

Fig. 7. Schematic illustration of the tabletop model used in Experiment 3.

\section{Results}

Figure 8 shows the results for 24 (those deriving from the combination of eight slope pairings and three horizon conditions) of the 55 conditions.

\section{No horizon}

A horizontal road was always seen as such when accompanied by an uphill; but when accompanied by a downhill, it was seen as uphill by 6 subjects out of 8 . A downhill road flanked by a steeper downhill road was seen as uphill by 7 subjects out of 8 (Fig. 8 , top panel, leftmost point; for the 8th subject, the illusion went in the same direction but was smaller, so that he reported the $3 \%$ downhill as slightly downhill, rather than horizontal, and the $1.5 \%$ downhill as horizontal, rather than uphill). This condition reproduced the illusion found at Montagnaga (Fig. 6). Actually, the slope of road that illusorily reverses at Montagnaga is about $1 \%$ (rather than $1.5 \%$ as in our experiment), and the accompanying road is $10 \%$ (much steeper than our $3 \%$ ), which makes the illusion absolutely compelling.

\section{Horizon on the road}

When the vanishing point of a road was seen on the horizon line, the road itself tended to appear level (as shown by the clustering of data points around the dashed line in the middle panel of Fig. 8). In this case, the perceived slant of the road nearby changed as though the two roads were solidly hinged. For example, a downhill road whose edges were seen to converge at the horizon became horizontal, and the flanking horizontal road was reported as uphill ( 7 subjects out of 8 ; the 8 th saw no illusion). Especially interesting is the case in which both roads were uphill (Fig. 8, middle panel, right-most point): The gentler incline was seen as horizontal by 7 observers, and as downhill by 1 . 

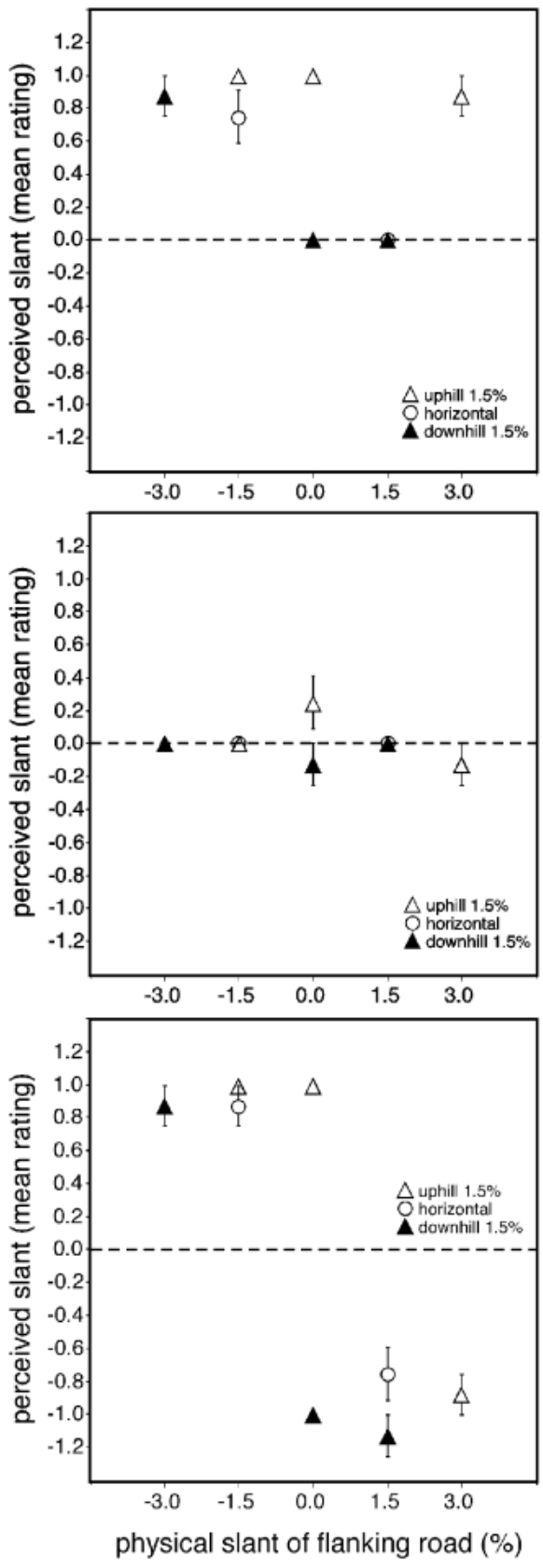

Fig. 8. Results from Experiment 3. Perceived slant (mean rating on the 5-point scale) of the test road is graphed as a function of the physical slant of the flanking road, for three different physical slants of the test road. Results are shown for three different horizon conditions: no horizon (top panel), horizon on the test road (middle panel), and horizon on the flanking road (bottom panel). Bars indicate the standard error of the mean.

\section{Horizon on nearby road}

Comparison between the top and bottom panels of Figure 8 shows that the presence of a horizon at the vanishing point of the flanking road had virtually no effect on the test road when the flanking road was a downhill (data points in the left half of each graph), whereas the horizon made an obvious difference when the flanking road was an uphill (data points in the right halves of the graphs). The simplest interpretation of this result is that the perceived slope of the test road depended on the relative position of the horizon. The horizon's position was, of course, lower than the test road when the flanking road was a downhill, and higher than the test road when the flanking road was an uphill. Horizons lower than the 
vanishing point of the test road would push it uphill-but the test road appeared uphill already, by virtue of the flanking downhill. In contrast, horizons higher than the vanishing point of the test road clearly pushed it downhill, something the flanking uphill could not do on its own (as shown by the no-horizon condition).

When the vanishing point of a steep uphill flanking road was seen on the horizon line, this road seemed level to 7 subjects out of 8 , and the gentler uphill stretch appeared clearly downhill (Fig. 8, bottom panel, right-most point; the 8th subject saw a weaker illusion in the same direction, reporting the $3 \%$ uphill as slightly uphill, and the $1.5 \%$ uphill as horizontal). This reversal reproduced the illusion found at Martina Franca (Italy), where a moderately uphill highway points toward a far hilly landscape, and a slightly uphill short stretch departing from the highway is erroneously perceived as downhill.

\section{EXPERIMENT 4}

In Experiment 4, we studied the case in which the spooky road consists of a single uphill stretch whose borders converge below a raised horizon line created by faraway hills. The road seems to be running downhill. The best-known site of this type, Electric Brae, is in Scotland. It has been suggested (Ross, 1974), but never experimentally tested, that the illusion is due to the height of the visible horizon.

\section{Method}

The stimulus materials consisted of three $16-\mathrm{cm} \times 10-\mathrm{cm}$ grayscale images, computergenerated starting from a digitized photograph and printed on separate paper sheets. The first was a photograph of the Electric Brae; the other two were generated by modifying this image with a computer graphics program so as to obtain different heights for the horizon line (see Fig. 9 for details).

The three images were presented in the frontal plane, in random order, to a new sample of 24 observers. They were asked to assess the slope of the road in each image on the same 5point scale used in the previous experiments.

\section{Results}

The mean ratings for the three conditions were significantly different from each other, $\chi^{2}(2$, $N=24)=14.15, p=.0008$ (Friedman two-way analysis of variance). The high-horizon road appeared downhill ( $M=-0.59$ ), the mid-horizon road appeared approximately level $(M=$ 0.08 ), and the low-horizon road looked uphill ( $M=0.67$ ). The high-horizon condition portrays the truly uphill view of the Electric Brae, which runs into a mountain background. In the natural counterpart of the low-horizon condition (the Electric Brae viewed from the opposite side), there are no low faraway hills at all, and the road meets a sky background, making for an even stronger illusion. 

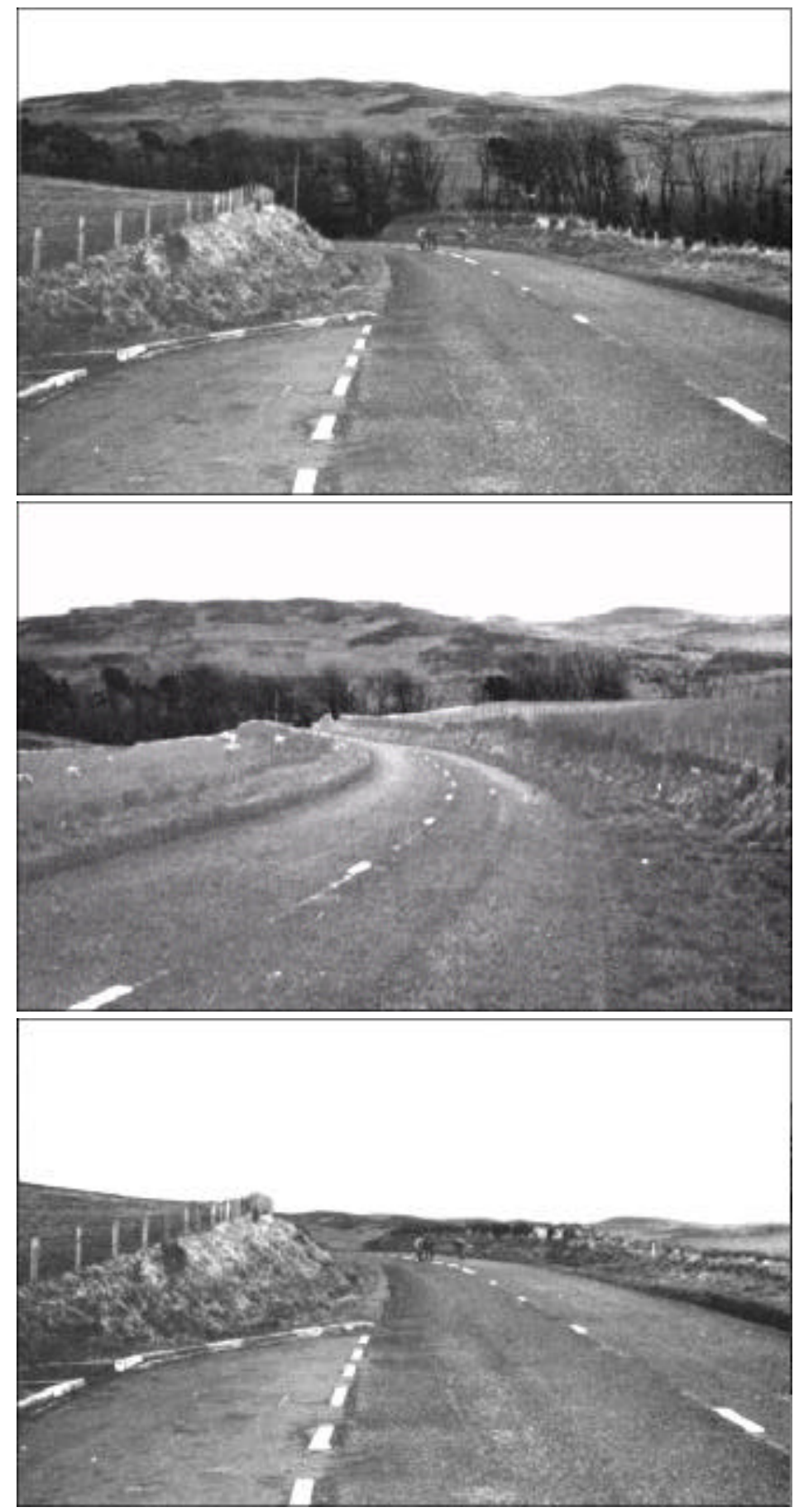

Fig. 9. The stimuli used in Experiment 4. The high-horizon road, shown in the top panel, is the original Electric Brae (after Ross, 1974). The road seems to be running downhill, below a raised horizon line created by hills in the background. The mid-horizon road, shown in the middle panel, was obtained by combining the Electric Brae viewed from the opposite end of the road (after Ross, 1974) with the horizon in the top photograph. The low-horizon road, shown in the bottom panel, was obtained by lowering the horizon line of the top photograph.

\section{GENERAL DISCUSSION}

Three of our results have a clear bearing on the issue of antigravity hills. First, slopes were underestimated, to the point that slight inclines were always perceived as horizontal 
(Experiment 1). Underestimation of slopes has also been reported by McDougall (1903). ${ }^{2}$ Second, perceived slope was an inverse function of the height of the visible horizon (Experiments 3 and 4). Third, perceived slant was affected by other slants: When accompanied by downhills, horizontal stretches were perceived as uphill, and slightly downhill slopes could also be seen as uphill (Experiments 1, 2, and 3). Underestimation was weaker for uphill than for downhill slopes, a result consistent with McDougall's (1903) data; however, slight uphills could be seen as horizontal when accompanied by much steeper uphills, and as increasingly downhill as the inclination of the accompanying slope increased (Experiment 2).

Assessment of slant is made relative to the eye level normal to the direction of gravity (GREL, or gravity-referenced eye level), which normally coincides with the geographical ("true") horizon plane. A plane is perceived as horizontal when it is parallel to GREL, and as slanted otherwise. In uncluttered conditions (e.g., in front of the sea or flat land), the judged eye level coincides with the visible horizon line. When the vanishing point of a road (the point where its borders seem to meet) viewed frontally is at GREL, the road will be perceived as horizontal; when the vanishing point lies below or above GREL, the road will be judged as running downhill or uphill, respectively.

However, the vestibular and postural information on which GREL is based can be contaminated by visual cues. It has been shown (for a brief review, see Stoper \& Cohen, 1989) that GREL is not always assessed veridically; it becomes biased in the direction of the eye level parallel to the ground plane (SREL, or surface-referenced eye level) whenever the two do not coincide, as in front of a slope. This is a large effect: Judged GREL is typically shifted approximately half of the way toward SREL, but much larger biases, up to $88 \%$, have been reported (Asch \& Witkin, 1948). We suggest that this compromise could account parsimoniously for all our findings.

First, a shift of judged GREL toward SREL will decrease the perceived angle of any incline relative to GREL, and hence the incline's apparent slant (explaining why slopes are underestimated). For small physical slopes, a shift of the reported magnitude would be enough to bring perceived slant under threshold (explaining why our $1.5 \%$ in- clines appeared horizontal). Second, SREL does not require proprioceptive information, but is specified by optical information alone - whenever possible, directly by the visible horizon (i.e., the line between the ground plane and the sky; Gibson, 1950; Sedgwick, 1980). This accounts for our finding that perceived slope depends on the height of the visible horizon. In the presence of a raised horizon line, such as that created by distant hills at Electric Brae and Martina Franca, SREL will pitch up from the horizontal, shifting judged GREL in the same direction and making a slightly uphill road appear downhill.

Likewise, by pitching SREL up or down, the presence of a steeper slope will bias judged GREL in the same direction, flattening or reversing the accompanying gentler slope, and explaining the dependence of perceived slant on contextual inclines. Our data suggest a bias

\footnotetext{
2 It has also been reported that the slant of inclines tends to be overestimated, rather than underestimated, relative to the horizontal plane-both in outdoor conditions, where hills look steeper than they are (Proffitt, Bhalla, Gossweiler, \& Midgett, 1995; Proffitt, Creem, \& Zosh, 2001), and in the laboratory (see Perrone, 1982). In the first case, slant angles were much larger than ours, and whether they slanted up versus down was unambiguous. In the second case, stimuli were either geometric figures on a homogeneous background or textured surfaces seen through a hole. It has been suggested that in these conditions, the observer's perceived straight-ahead direction would deviate toward the nearest part of the surface, altering the derived pitch angle (Perrone, 1982). Incidentally, in these experiments, surfaces were typically slanted $0^{\circ}$ to $90^{\circ}$, and could never represent a downhill plane.
} 
approximating 50\% when SREL is pitched up from the horizontal (1.5\% uphills accompanied by $3 \%$ uphills became horizontal), and larger than $50 \%$ when SREL is pitched down from the horizontal ( $1.5 \%$ downhills accompanied by $3 \%$ downhills became uphills).

\section{CONCLUSIONS}

We found that perceived slope depends on the height of the visible horizon; that surface slant tends to be underestimated relative to the horizontal plane; and that when preceded, followed, or flanked by a steep downhill slope, a slightly downhill stretch is perceived as uphill. The visual (and psychological!) effects obtained in our experiments were in all respects analogous to those experienced on site. After each observer's task was concluded, we placed a small roll of tape on the misperceived slope, and the tape appeared to move against the law of gravity-producing surprise and, on occasion, reverential fear.

The more than 20 natural cases of antigravity hills reported to date are all variations on a single theme. Our study shows that the phenomenon can be re-created artificially, with no intervention whatsoever of magnetic, antigravitational, or otherwise mysterious forces. The spooky effects experienced at these sites are the outcome of a visual illusion due to the inclination of a surface being judged relative to an estimated eye level that is mistakenly regarded as normal to the direction of gravity. Using miniature or even life-size reproductions of our tabletop models, it should now be easy to re-create the fascination of this challenge to gravity in amusement parks and, for twice the benefit, science museums anywhere.

Acknowledgments-We are grateful to Bruce Bridgeman, Dennis Proffitt, Dave Rose, and an anonymous reviewer for their critical reading of the manuscript.

\section{REFERENCES}

Asch, S.E., \& Witkin, H.A. (1948). Studies in space orientation: I. Perception of the upright with displaced visual fields. Journal of Experimental Psychology, 38, 325-337.

Gibson, J.J. (1950). The perception of the visual world. Boston: Houghton Mifflin. Gregory, R. (1998). Mystery spots. Editorial. Perception, 27, 503-504.

McDougall, R. (1903). The subjective horizon. Psychological Review Monograph Supplements, 4, 145166.

Perrone, J.A. (1982). Visual slant underestimation: a general model. Perception, 11, 641-654.

Polidoro, M., \& Garlaschelli, L. (2001). Investigatori dell'occulto. Roma: Avverbi.

Proffitt, D.R., Bhalla, M., Gossweiler, R., \& Midgett, J., (1995). Perceiving geographical slant. Psychonomic Bulletin \& Review, 2, 409-428.

Proffitt, D.R., Creem S.H., Zosh W.D. (2001). Seeing mountains in mole hills: geographical-slant perception. Psychological Science, 12, 418-423.

Rock, I. (1990). The frame of reference. In I. Rock (Ed.), The Legacy of Solomon Asch: Essays in Cognition and Social Psychology (pp. 243-268). Hillsdale, NJ: Erlbaum.

Ross, H.E. (1974). Behaviour and perception in strange environments. London: Allen \& Unwin.

Sedgwick, H.A. (1980). The geometry of spatial layout in pictorial representation. In M. Hagen (Ed.), The perception of pictures (pp. 33-38). New York: Academic Press.

Shimamura, A.P., \& Prinzmetal, W. (1999). The Mystery Spot illusion and its relation to other visual illusions. Psychological Science, 10, 501-507.

Stoper, A.E., \& Cohen, M.M. (1989). Effect of structured visual environments on apparent eye level. Perception \& Psycophysics, 46, 469-475.

(RECEIVED 1/29/02; REVISION ACCEPTED 11/15/02) 


\section{APPENDIX: TABLETOP MODEL USED IN EXPERIMENT 1}

Three plywood boards, A, B, and C, each $100 \times 80 \mathrm{~cm}$, were hinged to each other, producing a plane of $100 \times 240 \mathrm{~cm}$. The boards were accurately set horizontal on a large table $\mathrm{F}$ by means of a spirit level. Board $B$ could be tilted by inserting small blocks $\left(G, G^{\prime}\right)$ of the required thickness under the timbers $E$. Boards $A$ and $C$ could then be lifted or lowered independently by two lab jacks beneath them. By adjusting the height of blocks $G$ and $G_{-}$and that of the lab jacks, we could set the rises of the single stretches precisely; each rise was measured by a ruler placed vertically on the table surface, and touching the edge of the board.

The model was hidden by curtains, running along its sides, and illuminated by two fluorescent lamps producing a diffuse light, and no noticeable shadows. An opaque screen I, with a hole $L$ (a tube, $4.5 \mathrm{~cm}$ in diameter), was placed in front of the model, $30 \mathrm{~cm}$ from the nearest edge. In each condition, the viewpoint was $34 \mathrm{~cm}$ above the nearest point of the road, and allowed only monocular vision, with no parallax information; the model's edges were invisible.

A light-blue screen $\mathrm{H}$ was hung behind the model to simulate the sky. At the far end of board C, we arranged a few small model trees, to add to the realism of the scenery. The boards were covered with thick, smooth, textureless, green padded felt; on top of the felt, we laid a "road" M, cut out from tan-colored textureless paper. In real life, the edges of a level road, viewed frontally, are seen to converge at a vanishing point on the horizon, which is located by definition at the observer's eye level. Such convergence was simulated by cutting the paper in the shape of a long isosceles triangle $(30 \times 240 \mathrm{~cm})$. These measures were decided after preliminary observations of a real road using a protractor, which enabled us to measure the angle by which the edges of a 3-m-wide road are seen to converge at the horizon. 